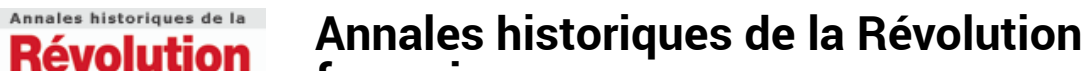

française française

337 | juillet-septembre 2004

Varia

\section{Histoire populaire de la chouannerie}

\section{Serge Bianchi}

\section{OpenEdition}

\section{Journals}

Édition électronique

URL : https://journals.openedition.org/ahrf/1563

DOI : 10.4000/ahrf.1563

ISSN : 1952-403X

Éditeur :

Armand Colin, Société des études robespierristes

Édition imprimée

Date de publication : 1 septembre 2004

Pagination : 221-223

ISSN : 0003-4436

\section{Référence électronique}

Serge Bianchi, «Histoire populaire de la chouannerie », Annales historiques de la Révolution française [En ligne], 337 | juillet-septembre 2004, mis en ligne le 15 février 2006, consulté le 23 avril 2022. URL http://journals.openedition.org/ahrf/1563 ; DOI : https://doi.org/10.4000/ahrf.1563

Ce document a été généré automatiquement le 23 avril 2022.

Tous droits réservés 


\title{
Histoire populaire de la chouannerie
}

\author{
Serge Bianchi
}

\section{RÉFÉRENCE}

François Cadic, Histoire populaire de la chouannerie, Rennes, Presses universitaires de Rennes, 2003, 2 vol., 601 et 598 p., ISBN 2-200-26275-2, $25 €$

Dans une préface nuancée, Roger Dupuy met en valeur les apports incontestables de cette somme de près de 1200 pages, rédigée entre 1908 et 1918 par l'abbé François Cadic, à partir d'une masse colossale d'archives et de témoignages oraux. L'édition complète de ces études parues dans La Paroisse Bretonne de Paris permet de mesurer le chemin parcouru entre les intuitions du professeur de l'Institut catholique de Paris au début $\mathrm{du} \mathrm{XX}^{\mathrm{e}}$ siècle et les acquis de la recherche universitaire actuelle. Une introduction suggestive présente la passion de l'historien, les racines familiales de ses motivations (des victimes dans les deux camps), la méthode de travail, sa volonté de réhabiliter les paysans bretons, de laver les chouans de la réputation de brigandage, sans céder à l'anathème et à l'esprit partisan. La lecture de l'ouvrage ne justifie pas totalement ces présentations positives.

2 Ce n'est ni un problème d'érudition, ni un problème de lecture. François Cadic connaît parfaitement son sujet, les hommes, les dates, les lieux de cette réalité complexe et éclatée que fut la chouannerie, entre la première révolte de Jean Chouan en Mayenne (août 1792) et l'apogée de l'Empire (en 1807). Il sait faire vivre le théâtre des opérations, dans une description suggestive du bocage et de la "singulière Armorique ». Il fait preuve de qualités évidentes de narrateur, ajoutant la précision des données (confirmées par de nombreuses notes) à l'art du récit, à l'abondance de citations sensibles, d'anecdotes édifiantes. On reste impressionné par la profusion de petits chapitres, souvent conclus ou parsemés de remarques générales, de jugements historiques. 
3 Il n'en demeure pas moins que l'ouvrage a vieilli, par sa conception générale et par son procédé d'analyse. Il se présente comme une succession chronologique de faits et d'événements descriptifs, à l'exception d'un état des lieux utile en première partie. Le caractère répétitif et haché des titres de chapitres, l'énumération des révoltes, des massacres, des répressions conduit à une impression de redite et de monotonie, malgré les variations du style. L'absence de carte et de tout bilan rend la lecture plus difficile. Le Morbihan est certes privilégié, par l'importance des forces engagées et les racines de l'auteur. Mais il faut avoir un Atlas à portée de la main pour ne pas se perdre dans les centaines d'escarmouches se succédant pendant près de 15 ans sans grande interruption, sur des espaces aussi divers que le Finistère, la région de Vitré, la Mayenne, la rive nord de la Loire. La réflexion sur la nature de l'insurrection n'est pas absente, mais comme diluée et masquée par la fréquence des conflits. Quelques erreurs factuelles (la loi des suspects) ou d'interprétation (les relations entre Jean Chouan et le marquis de La Rouërie) ne remettent pas en cause la qualité et la richesse de l'information.

4 L'ouvrage pâtît également des apports récents de la recherche historique. Il apporte des intuitions (le soulèvement spontané des paysans) là ou des auteurs ont dégagé des proportions et des pourcentages (Donald Sutherland et Roger Dupuy). Il ne propose guère de typologie des actions des chouans, laissant au lecteur le soin de rassembler et caractériser les tactiques et les cibles des bandes. Il ne met pas en valeur les grandes étapes de la chouannerie et l'importance de l'insurrection du printemps 1799 (de l'an VII) où plus de 30000 chouans (dont huit légions), passés dans la Contre-Révolution prennent des villes qu'ils n'avaient pu conquérir jusqu'alors. Mais il reste alors muet sur les résurgences de la chouannerie mayennaise, qui pourrait compter sur près de 4000 hommes.

5 L'ensemble donne une impression de dénigrement quasi systématique des républicains et des bleus, des jacobins, terroristes et sans-culottes, puisqu'on retrouve parfois l'écho de la haine enflammée d'un Taine, que l'abbé Cadic avait lu et médité. Il est question des « hystériques qui composent la cohorte jacobine» (p. 25), des bandes d'assassins et des féroces massacreurs, du bourreau qui ne cesse d'abattre des têtes de prêtres et de catholiques. Dans le même temps, l'auteur ne légitime pas tous les actes des chouans. Il stigmatise les assassinats de certains maires, juges de paix par les Blancs, condamne les actes qui disqualifient leurs auteurs, sauf dans le cas de faux chouans. L'éloge du général Hoche, d'un instituteur qui prône la clémence montrent des réserves et la gêne face à des excès qui favorisent une opinion contemporaine défavorable au brigandage, au cœur de la Bretagne.

6 Mais le manque de recul introduit des jugements discutables. D'un côté, François Cadic justifie les révoltes paysannes contre la république, mais il traite parfois les révoltes de 1790 de "saturnales sauvages" des meutes populaires contre la propriété. Il ne reconnaît aux paysans bretons qu'un défaut, le braconnage. Il ne reconnaît par contre aucune qualité aux prêtres constitutionnels, abjects pour avoir contesté l'autorité du pape. Sa défense et illustration du clergé séculier réfractaire est en partie hagiographique et se rattache à un véritable martyrologe.

7 Mais la lecture n'est pas univoque. François Cadic met l'accent sur des phénomènes peu connus; l'importance des kloarecs, jeunes gens élevés dans le petit séminaire de Vannes. Il signale, au détour d'une ligne, le rôle particulier joué par tel juge de paix, ou tel acquéreur de biens nationaux. Il met en valeur le rôle des communautés, la place des 
femmes dans les révoltes. Il pointe des tentatives de rapprochement entre la bourgeoisie et les paysanneries au moment de la fête de la fédération de juillet 1790 , précédée des fédérations bretonnes de Pontivy. Il pose la question cruciale du basculement d'une paysannerie non hostile à la Révolution dans les premiers temps vers un comportement de guerre civile trois ans plus tard.

8 Au terme de ce survol, se pose la question de la pertinence d'une telle édition. Dans la mesure où elle revient à nier des acquis de la recherche contemporaine, elle peut sembler discutable. L'histoire des lendemains de la séparation de l'Église et de l'État et des inventaires a beaucoup évolué de nos jours. Surtout, il manque une voix contradictoire, qui donne la parole aux détracteurs de la chouannerie, expliquant les silences des commémorations "blanches" dans certaines régions d'élection, à l'exception du Morbihan, de Vannes, Saint-Anne d'Auray et Quiberon. La perception des changements à l'égard de la religion et du culte a changé. On prend aujourd'hui en compte les tentatives de cultes révolutionnaires, de conciliation entre les idéaux chrétiens et ceux de la morale révolutionnaire puis républicaine, les mariages et les abdications des constitutionnels. Les synthèses récentes sur la chouannerie nous paraissent dévaloriser le travail de François Cadic. Cet auteur impose toutefois au fil des pages un souffle, une sensibilité qui forcent l'admiration, à condition de disposer d'un recul historique suffisant et de prendre ses distances avec certaines idées datées, certaines traditions orales. La réhabilitation de la race bretonne, robuste, gaie, de sa culture populaire (chansons, poèmes), de l'amour infini de la paroisse, du prêtre et de la liberté face à une bourgeoisie manipulatrice et gangrenée par les dogmes des philosophes et des franc-maçons : voilà qui ferait sourire, si dans le même temps, l'auteur n'avait montré de solides qualités d'analyse et des capacités de nuances indéniables. Faire le tri tout au long des 1200 pages d'un texte aussi foisonnant relève de la gageure. Nous saluerons donc l'initiative des Presses Universitaires de Rennes, sans dissimuler au final un sentiment mêlé de perplexité, de respect et de réserve. 